Journal of Social Sciences 7 (4): 475-484, 2011

ISSN 1549-3652

(C) 2011 Science Publications

\title{
Navigating two Worlds: New Identity Constructions as Determinants for Successful Integration of New Black Immigrant and Refugee Youth in Canadian Society
}

\author{
Michael Baffoe MSW \\ Faculty of Social Work, 500B Tier Building \\ University of Manitoba Winnipeg, Manitoba, Canada R3T 2N2
}

\begin{abstract}
Problem statement: The interest in immigrant children and children of immigrants has been growing recently. There is a gap in the literature on current knowledge on the integration and adaptation conditions of the new second generation of immigrants. For teenage youth growing up in diaspora settings, the issue of identity becomes paramount. Approach: They come to define themselves, as well as how others define them, had important implications for social work practice. Immigrant children and youth were the fastest growing component of child and youth population in Canada. Results: We explored the pertinent issue of identity construction as a significant variable in the integration and settlement challenges that Black immigrant youth face in Canadian society. Conclusion: The article is based on an ethnographic study of a number of Black immigrant youth in two of Canada's largest cities, Montreal and Toronto, the popular settlement points for many new immigrants to Canada.
\end{abstract}

Key Words: Immigration Canada, refugee youth, identity construction, successful integration, Canadian society, ethnic identity, research questions, ethnic boundaries, ethnic groups, minority youth

\section{INTRODUCTION}

The article draws from a research project designed to investigate some aspects of the difficulties that Black African immigrant youth undergo in their attempts to integrate into Canadian society. It focuses on the critical issue of identity construction and the struggle to fit into new cultural milieu by new Black immigrant and refugee youth in Canadian society. It reviews some of the existing literature on identity and identity construction of immigrant youth and their relationship to immigrant integration and adaptation. Secondly, the frameworks upon which this study was anchored and the research methodology employed in this study are presented. Thirdly, the research methodology employed for this study is discussed. It then examines the issue of "identity" deconstruction and reconstruction among ethnic minority immigrant youth in Canada and the struggle to "fit in" into the new cultural milieu. A portrait of the family dynamics of these youth that are put under severe strain because of the tension and struggles associated with the integration and adaptation process are also examined. These are backed by some interesting narratives from some of the youth, community leaders and parent participants in the study. I conclude with an analysis of the findings from the study and recommendations for social work intervention with these new immigrant youth in Canadian society.

Census Canada figures released in March 2009 show a dramatic increase in Canada's population, $5.4 \%$ (1.6 million, the highest in any of the G8 Industrialized countries), over the last five-year period, (2003-2008). Sixty percent of this population increase is attributed to immigration. The new demographic reality of Canada is that Asian and African immigrants have replaced the old European stream and have changed the demographic face of Canada (Statistics Canada, 2009). These changing demographic trends in Canadian society with "visible minorities" (including Blacks) forming a significant proportion of the Canadian population underscore the need to examine certain critical areas that affect the integration of a section of the new immigrant population in Canadian society. This is the community of Black new immigrant youth who are part of the second generation of immigrants in Canada. The second generation of immigrants refers to children of contemporary immigrants who are born to immigrant parents in the diaspora. For the purpose of this study, the focus is on contemporary immigrant children who have arrived in Canada before they reach adulthood. This group of immigrant youth, who are mostly in their early and mid-teenage years are now referred to as the "one-and-a-half generation" (or the 1.5 generation). This term is now used to characterize 


\section{J. Social Sci., 7 (4): 475-484, 2011}

immigrant children who straddle the old and the new worlds but are not fully part of either (Rumbaut, 1994). Many scholars on immigrant experiences agree that the one-and-a-half generation of immigrants have distinct physical and psychological developmental stages in their socialization processes in the family, the school in the new homeland and the society at large as well as their memories and attachments to various sociocultural aspects of their original homelands (Zhou, 1997; Portes and Rumbaut, 1996; Firmat, 1994; Portes and Rumbaut, 1996; Moss et al., (2010).

Identity of visible minority immigrant youth: For the immigrant youth, especially the teenage youth, successful integration into their new society depends to a very large extent on the maintenance of a positive identity of themselves or a reconstruction of a newer identity that is shaped and controlled by their desire to fit into their new society... and quickly. Identity is defined as a feeling, inter-subjectively shared by individuals in a given group that is based on a sense of common origin, common beliefs and values, common goals and a sense of shared destiny (Suarez-Orozco et al. (2004). Identity has two components: Personal Identity, which refers to how one views himself/herself (determination and choice), is influenced to a large extent by the dominant ideologies. There is also Social Identity which refers to how the society/world around us views us. How society views us have a great influence on how we view and see ourselves.

Ethnic identity: The issue of identity is an important one for all immigrant youths and particularly for children of color because it establishes the psychological reference points and ability to cope with the discrimination and prejudice to which children of color are subjected in Canadian society. Nagel (1994) points out that individuals and groups attempt to address the problematics of ethnic boundaries and meaning through the construction of identity and culture. The construction of ethnic identity and culture is the result of both structure and agency, a dialectic that is played out by ethnic groups and the larger society. Nagel (1994) argues that although ethnicity is the product of actions undertaken by ethnic groups as they shape and reshape their self-definition and culture, ethnicity is also constructed by external social, economic and political processes and actors. This constructionist view of identity also posits that through the actions and designations of ethnic groups, their antagonists, political authorities and economic interest groups, ethnic boundaries are erected dividing some populations and unifying others (Barth, 1969; Turner,
1974). Ethnicity is thus constructed out of the material of language, religion, culture, appearance, ancestry or regionality. The location and meaning of particular ethnic boundaries undergo continuous negotiation, revision and revitalization both by ethnic group members themselves as well as by outside players, observers or authorities (Nagel, 1994).

These ethnic boundaries determine who is a member and who is not and designate which ethnic categories are available for individual identification at a particular time and place. As Appiah and Gutmann (1998) point out, racial and ethnic identities are achieved and ascribed. Identities are achieved when there is a sense that this "identity is mine....I can choose how central my identification with it will be, choose how much I will organize my life around that identity" (p. 80). Ascription of group membership has two main sources: those made by group members ("you are a member of our group") and those made by the majority group (you are a member of that group").

Suarez-Orozco et al. (2004) maintains that negative distortions of the social mirror have profound implications for the development of identity among members of ethnically and racially marked groups. Nagel (1994) further argues that ethnic identity can be both optional and mandatory since individual choices are often circumscribed by the ethnic categories available at a particular time and place. Some of these categories, usually those of the minorities, are often stigmatized with certain disadvantages placed on them. This therefore makes the retention of this identity unattractive to the youth within such ethnic groups. As Phinney (1996) also points out, ethnic identity, for minority youth growing up in a new society, is a complex cluster of factors including self-labeling, a sense of belonging, positive evaluation, preference for the group, ethnic interest and knowledge and involvement in activities associated with the group. This means that the strength or degree of one's ethnic identity is significantly influenced by factors such as the language spoken in one's home, the ethnic composition of one's neighborhood and the percentage of one's friends who are in the same ethnic life (Boykin and Toms, 1985).

Adaptation outcomes, according to Portes and Rumbaut (1996), are also determined by structural conditions in the host society. For the one-and-a-half generation of immigrants, these contexts pose even more challenges. Among some of the top challenges is the process through which these particular immigrant population groups navigate their way to be able to define and consolidate their identity in their new environment. 


\section{J. Social Sci., 7 (4): 475-484, 2011}

Theoretical framework for research: The research draws its theoretical foundation and strength from the body of literature on critical race theory and its tenet of counter-storytelling and ethnic identity construction. McDonald, (2003) points out that critical race theory explicitly focuses on social inequalities arising through race and racism. For this study I drew on two tenets of critical race theory. First, critical race theory works to name and discusses the daily realities of racism and expose how racism continues to advantage Whites and disadvantage people of colour, designated officially in Canada as visible minorities (Dei, 1998). Secondly, it legitimates and promotes the voices of people of colour by using storytelling to integrate experiential knowledge drawn from a shared history as 'the other' into critiques of dominant social orders (LadsonBillings, 1998). For the participants in this study who were struggling to navigate a new educational and cultural system of their new society, this aspect of critical race theory is very pertinent.

Although race and racism are at the center of a critical race analysis (Dei, 1998), Solorzano and Yosso (2002) also posit that race and racism should be viewed at their intersection with other forms of subordination such as gender and class discrimination. For the visible minority youth in this study, the layers of subordination based on race, gender, class, immigration status, surname, phenotype, accent and sexuality all intersect to shape their difficult navigation experiences in Canadian society. What they have in common with other people of colour is what Ladson-Billings (2000) calls, the "experience of a racialised identity" (pp. 262).

I draw on the tenet of counter-storytelling to privilege minority immigrant youth, especially Black African immigrant youth in Canada, because I consider them as expert knowers in their own struggles to "fit in" into their new society. Furthermore, these counterstories serve to illustrate the potential of critical race theory in assisting in understanding the world of visible minority youth in Canadian society. This is illustrated by the powerful narratives from some of the study participants which will be presented later in this article. Despite attempts to marginalize race in much of public political discourse, race continues to be a powerful social construct and signifier (Ladson-Billings, 1998). This study therefore places the marginalized participants at the center of analysis and in so doing focuses on capturing the rich stories, counter-stories and narratives of these visible minority youth which illuminates their lived experiences in Canadian society. The participants in this study therefore get the opportunity to name their own lived realities which sometimes bring them into conflict with their own families. Counter-story-telling is therefore epistemologically valuable in understanding the lived experiences of visible minority youth in Canadian society.

Research questions: Bearing in mind that the ethnic minority immigrant youth constantly contend with the fact that they are culturally, ethnically and racially "other" Steele (2004), this study was framed around the following primary research questions: 1. What expectations, hopes or aspirations did these Black African immigrant youth have in coming to Canada and what do they do in the new society to realize these aspirations? 2. What roles, if any, do their original cultures play in aiding or inhibiting their adaptation to the social-cultural and educational systems of their new society? 3. What roles do the families and communities of these youth play in their integration processes? 4. How do transformations in racial and ethnic selfidentities affect the integration of visible minority youth, especially Black African immigrant and refugee youth, in Canadian society?

\section{Research methodology:}

Discovering through qualitative research: A qualitative research approach was the preferred choice in this study because it falls in the realm of phenomenology which, according to van Manen (1990), is the study of lived experience. Reflection on lived experience is always recollective; it is a reflection on experience that is already passed or lived through (van Manen, 1990). This study is therefore about the lived experience of its participants: Black African new immigrant and refugee youth in Canadian society. The context of these issues within which this study falls, include questions about how social life is organized and about the ways in which individuals and groups (new immigrant and refugee teenage youth) make sense of their lived experiences, both from their country of origin and in their new society and environment in Canada (Miller and Dingwall, 1997).

The study was contextualized in concerns about the role of cultural identity deconstruction and reconstruction of minority youth within the context of an unequal society (Carspecken and Apple, 1992). The research design and methodology therefore recognized the participants (new Black African immigrant and refugee youth) as expert knowers in their own lived experiences. The research process therefore recognized the expertise of the participants, their families and community leaders through interviews which explored their ideas and understandings about what constitutes real integration for them in Canadian society. The study participants were selected from a number of focus group discussions and series of interviews with 


\section{J. Social Sci., 7 (4): 475-484, 2011}

community leaders from a number of African communities in Montreal and Toronto, through a random sampling process from the large pool of potential participants that had been obtained from the earlier focus group discussions. In the final analysis, twenty-five youth (fifteen male and ten female), six community leaders and ten parents were interviewed for this study. Their countries of origin were five different African countries: Ghana, Nigeria, Cameroon in West Africa, Congo and Kenya in Central and East Africa. All the youth participants in the study had, at the time of the study, lived in Canada for periods ranging from four to six years. They had migrated to Canada either as sponsored immigrants by their families through the Family Re-Unification Program of Immigration Canada or had arrived together with their parents as refugee families. The minimum age range of settlement (four years) was deemed necessary to allow for some form of de-acculturation and acculturation to have taken place since their arrival in Canada.

The researcher had lived for a number of years in the two Cities from which the research participants were drawn and knew some of the leaders of the African communities in those cities. A number of community leaders were contacted who provided names of other community members (adults) who were contacted later to participate in focus group discussions. Two focus group discussions were held, one with leaders from the West African Communities of Ghana, Nigeria and Cameroon which consisted of fifteen participants. The second focus group discussion was held with leaders of the two East and Central African communities of Kenya and the Congo which consisted of ten participants. Out of this pool of community elders, six were randomly selected for the final one-onone interviews. The youth participants groups were formed through an initial list supplied by the community elders and word of mouth invitation from some of the youth to their friends who agreed to be part of the youth focus group discussions. Two focus group discussions were held over a three-month period with the youth. Each group had twenty participants. Out of these, a final youth research sample of twenty-five was randomly selected for the one-on-one interviews all which lasted between one-and-a-half and two hours.

Findings: From this study on the integration efforts of Black African immigrant youth in Canadian society, the following stages of the integration process were identified: Excitement and Hope Stage; Stage of Identity Confusion; Negotiation Stage; Cultural Clash/Alienation; Stage of Deconstruction/Rejection of old cultural identity and Reconstruction of New
Identities. Also identified was the craving of the youth for positive role models in their new society.

Early life in Canada: excitement and hope stage: All the youth participants in this study arrived in Canada in their early or mid-teenage years either as part of a refugee family or sponsored by their already settled parents under the Family Re-unification program of Immigration Canada. This first stage of their integration process is characterized by excitement. The African new immigrant youth is excited about "landing" in the "promised land". This stage is characterized by a sense of fulfillment. All the "good" things that the youth has watched on television about Canada are now within his/her reach. It is only a matter of time. The second stage involves hope: hope of a better life looming on the horizon. The new immigrant youth goes to school. He/she sees the new life around $\mathrm{him} /$ her and feels good. Hope looms on the horizon that in a few years most of his/her dreams of a better life will become reality. These early stages of excitement and hope do not last long before the youth reached the third stage of integration which formed a major part of this study, the stage of Identity Confusion.

Stage of identity confusion: After socializing in school and in the new neighborhoods with friends and peers (from his/her ethnic background and mainstream) for a while, the new ethnic minority immigrant youth runs into confusion about his own place in the new society. The lifestyles of his peers are different: the new cultural environment that includes language skills, mode of dressing, food and music are all totally different and strange at times. The new immigrant youth gets messages that his/her place in the new society is marginal at best (Burpee, 1920). He/she gets torn between his own culture and identity as a teenage youth and the pull and attraction of the new cultural environment. The raging identity and integration confusion brings the youth to the next stage of the process that involves tough balancing acts of negotiations.

Negotiation stage: At this stage, the youth tries to copy and adopt new lifestyles, that of the new society and even of his/her peers from his/her own ethnic background who have "already fitted-in" in an attempt to also "fit in". It is a tough balancing act of negotiation between himself, his family, his community and the new societal environment. This process therefore does not work for the struggling new African immigrant youth. Adding to the confusion at this stage is the fact that the family, out of fear of losing the youth to the 


\section{J. Social Sci., 7 (4): 475-484, 2011}

powerful cultural pull of the mainstream society, also tries to set boundaries and agenda as to how far the youth can move in terms of adopting new lifestyles. This process propels the youth to the next phase of the integration process, a stage that creates more tension and stress for the immigrant families.

Cultural clashes, alienation and Identity loss: It was very evident from the study that immigrant communities place very high premiums on cultural values which they regard as the cornerstone for establishing a sense of identification, affiliation and belonging to a community. For the youth, however, cultural values concurrently served as the source of tension and internal struggles when they had to juggle competing and opposing cultural values. The youth feel that there are contradictions between the cultural norms required at home and the values they acquire in the social settings of the new society and in their schools. The issues of cultural clash, cultural alienation and identity loss resonated throughout the research. The discussions with the youth revealed many areas of potential conflict between the heritage and host cultures. The fundamental conflict was found in the distribution of power and control between the parents and children, individual and community. The youth expressed their discomfort and dilemmas of being torn and pulled apart by two different cultures: that of their original culture (which most describe as their "parents' culture") and the culture of their new society which ironically, is not yet theirs. The new society's cultural pull becomes stronger because of their need to 'fit in' or be accepted by their Canadian peers.

While the youth participants described the phenomenon as a "clash of cultures" leading to cultural confusion, parents and community leaders saw the phenomenon as "cultural alienation" and "identity loss" of the new Black African immigrant youth to the new society's powerful cultural pull. The outside influence in the end exerts much stronger influence. Those who adopt the cultural ways of the host society become alienated from the family structure. They are seen as culturally lost. Those that stick to the family structure and cultural values are also isolated from their peers. Most of the youth saw "control" by their parents as one constant source of tension. They find that they cannot make their parents understand and they decide not to communicate with them.

When parental control creates resentment among some youth, they try to develop ways to reject the parental authority and find their freedom. The youth think that the norms of their parents are too conservative. They think that their parents do not have the knowledge, understanding and experience of the reality of the streets of Canadian society to understand their social worlds. They think their parents are still glued to and associated with, "how it was in Africa" (or their countries of origin) instead of "how it is in Canada" (their new society). My observation from my interaction with the youth in the informal and formal focus group discussions were that the new arrivals become totally confused in terms of where they belong, culturally-speaking. For the Black African youth in this study, their "rejection" of the old cultures is not a deliberate "rebellion" or contempt for parental, family or community authority. It is simply a struggle and desire to "fit in" and be accepted by their established ethnic peers as well as their Canadian peers. One youth, referring to the underlying problems in parents' attitudes towards adaptability put it this way:

Our parents, they think that they are still in Africa. They (parents) have trouble in accepting that life here is different, you go out and you meet your friends and you are different, hei, you get teased. It is we (the youth) who struggle with our friends out there. Our parents they only go to work and come home. They don't understand what man is out there, It's tough

Whichever way the various participants viewed the issue, the clash of cultures with its resultant confusion or alienation of the newly-arrived youth from their families and communities, affected the adjustment of the new Black African immigrant and refugee youth into Canadian society. During this period of Cultural Clash/Alienation, the stronger pull of the new cultural environment prevails over that of the new African immigrant youth. This stage brings the youth in conflict with the parents who fear losing the children to the "strange" and "dangerous" culture of the new society. This is a period of heightened conflict between youth and parents.

The frightened and more confused African immigrant parents have been known at this stage to resort to desperate measures to keep the youth in line often using physical disciplinary measures deemed illegal and unacceptable by mainstream society and its legal and social service systems. The situation often leads to the involvement of social service agencies in the lives of the African immigrant families. The youth is either removed from the family home and placed in foster care or may lead to the youth breaking away from the family home. The new peers become his/her "family". The situation often lands the youth with the wrong crowd and may lead to criminal behavior and conflict with the law. 


\section{J. Social Sci., 7 (4): 475-484, 2011}

Deconstruction/rejection stage: The next stage of Deconstruction/Rejection of old cultural identity sees the youth now rejecting his/her old cultural identity to be able to fit-in with his/her peers. They now regard their families and community as outmoded bunches who live in the past clinging to the "outmoded" customs of their original African homelands.

Stage of reconstruction of new identities: The youth then moves to the final stage of Reconstruction of New Identities at which time a complete break with the old culture and adoption of that of the new society occurs. The youth participants in this study now refer to their old culture as "My Parents' Culture". He/she regards the culture of the new society as "my" culture. He/she may believe, rightly or wrongly, that he/she has now been "accepted" by the new society.

It was evident from this study that the Black African immigrant children and their parents tend to perceive their host society and their relationship with it from different angles (Zhou, 1997). The youth tends to focus on current adjustment, paying attention to the external traits of what they come to define, according to the participants in this study, as "Canadian". They struggle to fit in based on a frame of reference that they have acquired from their Canadian peers and from their already-established ethnic peers. The process encompassed their visible racial status, different cultural and religious practices and family norms. Growing up as a visible minority person in Canadian society required these youth to confront issues of racial stereotypes and ethnocentric assumptions and to reconcile how these attitudes situated and positioned them in society. The issue of fitting in is a complex phenomenon that reflects how these youths face the challenges of negotiating and situating themselves within and between two social and cultural contexts. Each context presents its own distinct issues regarding minority status and reflects the dilemmas of simultaneously being an insider and outsider in both worlds.

The youth constantly referred to some of the tensions that arise for them as ethnic minority adolescents in Canadian society which made them feel awkward and socially isolated. At school they are often intimidated, harassed and teased by other children. They are asked things like "why don't you speak English properly?" (teasing them about their accents). In addition they also report facing a level of indifference from school officials to their concerns, thus leaving them feeling socially isolated. The message that gets communicated to these newly-arrived visible minority children in the schools and the larger host society is that it is assimilation, rather than integration, that is required in order to fit in and be accepted.
The above shows that the first major effect of migration and settling in a new society for young people is to be thrust into a complex situation of growing up in two distinct cultural contexts encompassing the home, the school and/or the larger society (Portes, 1996; Portes and Rumbaut, 2001). These dilemmas arise in the face of competing social and cultural values from the host society, pressures to assimilate and racist attitudes from their peer groups, school and other service professionals they frequently encounter in the first few years of their settlement in the new society (Das, 1998).

It was clear from the study that Black African immigrant children in Canada constantly confront a reality in their host society where their ascribed physical features also become a handicap (Waters, 1994; Portes, 1995). They are not only often rejected by their White peers but, ironically, sometimes by their peers from their own ethnic backgrounds who have already "fitted in". This rejection is usually based on racial (ie. physical) features and cultural practices leading to lowered self-esteem, self confidence and a lowered sense of ethnic pride. The outcome of these experiences, as confirmed by youth, community leaders and parent participants, have resulted in either leaving the adolescents feeling alienated from their home, culture, ethnic community and school, or contributed to the development of a bicultural identity as a coping strategy.

The processes of cultural adaptation can be partly understood by the level to which members of minority groups socialize in their own communities and the extent to which social networks extend beyond the ethnic community. For the youth participants in this study, school is the primary cultural and acculturating institution where most contact with the new culture is made. The learning environment in North American schools also advocates different cultural attitudes such as autonomy, critical thinking and independence (Ghuman, 1991). These values are usually contrary to those taught and adhered to in most new immigrant ethnic minority cultures where interdependence, deference to authority and adherence to tradition are prioritized and encouraged.

For the youth participants in this study, the host society's values of autonomy and independence are very attractive and many wished, loved and tried to varying degrees, to take advantage of that in an attempt to be seen by their mainstream peers as having "fittedin'. However, that always comes with a heavy price from their families and ethnic communities. The youth complained that their parents were often scared that they were learning the "ways" of Canadian society "too 


\section{J. Social Sci., 7 (4): 475-484, 2011}

quickly". The youth were constantly reminded by their parents and community elders of their duty to show respect for their elders, to take care of younger siblings, to work hard, study hard in school and to make decisions upon approval of parents, not only within their particular families, but in their larger community. They were required to refer to all other community elders as "uncles" and "aunties". The youth participants in this study regard these family and community supports as insufficient to aid their desire for rapid "fitting in" into the new society.

Reconstruction of new identities: The clash between school culture and home culture is actualized in at least two ways. When a significant difference exists between the students' culture and the school's culture, teachers can easily misread students' aptitudes, intent, or abilities as a result of the difference in styles of language use and interactional patterns. The points out that, the schools do not usually understand or validate the cultural standards and values of these new immigrant youth seeing them as anti-social. Secondly, when such cultural differences exist, teachers may utilize styles of instruction and/or discipline that are at odds with community norms. It is this issue of cultural clash and alienation that has also become the constant source of tension between parents and the youth that leads to the intervention of social services. Many new immigrant families have been torn apart as a result when children are removed from their homes by the social services system for "protection" and placed in foster care or group homes because of conflicts with their parents. This view was expressed more forcefully in the focus group discussions, when most of the youth participants recounted that: We are under constant pressure from our parents to dress 'appropriately' when we go out. I guess they are worried that we will dress like other guys on the streets. So you kind of worried anytime you want to go out as what to wear because my Mom especially, she is always checking what I am wearing when I am going out. But you've got to understand that sometimes we also need to dress cool like the other guys. You don't want be isolated when you meet your friends... you know.

For many new immigrant and refugee youth this issue of cultural adaptation is a difficult no-win situation. They are in constant crisis, struggling and torn between two opposing cultural values. Many have developed "double personalities" as they expressed, one for display at home to please their parents and another outside to enable them "fit in" and get accepted by their peers. The issue of dressing is even more powerful for the new immigrant teenage girls. One female youth participant recounted that.
My Mum will always scream, 'go change that dress. You are not going out in this'. The next time she will say. 'what is this? You're going out with this?' So sometimes I will hide some clothes in my bag or behind the house and pick them as soon as I close the door. These were the ones that I will wear later when I go out with friends. And I will take them off and hide them in my bag before I got home.

The parents, however, see it differently. They feel their children were getting "lost" to the new system. They were frightened that the children were losing their cultural identity.

One parent put it this way: I believe that those children who are able to maintain their cultural identity are able to go through the system very successfully because they know (who they are)... that in my country and culture we don't do this and that. But those that are influenced who want to put away their culture and adopt a new culture get into problems because in the end they are not able to integrate well to the new culture and they get lost. I believe that those that become delinquent in a way are those that lose their cultural identity.

Another parent re-enforces this view she had this to say: Our cultural family structures expect the youth to have collective family values. But it becomes very difficult for the children when they arrive in Canada. While the family wants them to behave according to our traditional values, the host society pulls them in the opposite direction. The system here teaches them individuality and self-reliance while our culture is based on collective family responsibility. The kids gets torn between these two opposing structures and in the end, the strong appeal of the host society's independence-oriented culture has more influence on the children. They keep telling us that here is not Africa and we cannot bring them up like we were brought up.

Some parents have developed mechanisms to regulate controlled socialization of their children. Initially they try, when the children first arrive in Canada, to ensure that the children interact more with their own kind than outsiders. They take the children to visit families on weekends or attend cultural events. Occasionally, at Christmas and Easter times and during their communities' "national day" celebrations, they organize parties to which parents and children from their ethnic backgrounds are invited. For the teenage youth, however, these ethnic parties and community cultural events do not seem to be the right substitutes for going out and hanging with their peer groups. Besides the integration stages identified above, another 


\section{J. Social Sci., 7 (4): 475-484, 2011}

significant finding from the study was the absence of positive role models in Canadian society for the Black African youth.

\begin{abstract}
Absence of role models and positive media images: The absence of role models for the Black African immigrant youth in Canadian society, especially in the school system, was a theme that ran through the responses of most of the research participants and this was seen as one of the powerful indicators that affected their identity reconstruction and place in Canadian society. The youth participants spoke about how they encountered very few positive images on television and in the media about ethnic minorities. Some said that they were confused about the images they saw on television about their ethnic group, especially Black people, that offered no positive points of reference for them. There appeared to be no place (aside from their individual families or community) where they could identify or connect to being Black and see positive images of their ethnicity. The Black youth were particularly disturbed about the portrayal on television of Black people as the only ones that committed crimes. They were also concerned with the absence of teachers from their cultural backgrounds in the schools. They also contend that they do have people in positions of authority in the schools to advocate for them.

Parent participants and the community leaders also felt very strongly about the absence of positive role models for minority youth in the school system especially among the teachers.
\end{abstract}

One community leader had this to say: Some of us came here as foreign students not expecting to see a Black man standing in front of the class to teach us. But now the situation has changed and this issue of "role models" is becoming very important for the new generation. So the presence in the classrooms of people like us will make a difference. It will show the kids that they have a chance. They need to tell themselves that "yes we have Mr. Osam in this position so when I also finish school I have a chance".

Another community leader added: If people from the ethnic communities were found in the school system, the kids will see them as a point of aspiration. That will encourage them to stay in school. But since they don't see them they see the school system as strange. They don't see anyone like them.

Therefore with few ethnic minorities to identify with, few or no role models or mentors and no positive public or media image of their ethnic groups in
Canadian society, the youth wonder and agonize whether it is worth trying to go to school or remain there to achieve anything which in the end will take them nowhere. This agony and what they perceive as the reality of life in Canadian society flies in the face of the constant admonition by their parents on them to stay in school since education is the only road to achieving success in their new society. The question many keep asking is "success in what and for what"? The youth constantly asked why they should make the extra effort to excel in school if they cannot determine if the learning will ever be valued, seen or acknowledged. Why should they focus on learning, as their parents continuously drum into their ears, if the learning will not inform, affect or alter their status in the long run?

Implications for social work practice and recommendations: The implications of these findings for social work practice are very critical. It is important for social work professionals to acquire and display a much-better understanding of the difficult transitions which these new African immigrant families in Canada are navigating. It calls for advocacy on the part of social work professionals to assist these families undergoing difficult tensions to resolve issues without tearing apart the families with the quick removal and placement of immigrant children away from their family homes into foster care and group homes. These acculturation struggles involving immigrant children, their families and communities underscore the urgent need for social workers to act as cultural brokers between these struggling immigrant groups and the social systems of their new societies.

Social work practitioners in Canada, especially those that work in the child welfare system often display a complete lack of understanding of the circumstances and difficult terrain that new immigrant youth and their families navigate for survival in Canada. They are quick to pathologize these immigrant youth and their families experiencing acculturation stress. The constant removal of these youth from their families and placing them in foster care and group homes do nothing to address the underlying causes of the acculturation stressors.

It is also important for social workers to recognize that racism and discrimination in Canadian society, including those displayed by the social work professionals create further stress and hardships for these population groups. When new immigrant and refugee youth, like the Black African youth in this study, continue to experience racism and discrimination in their new societies, they never feel like they belong and the negative feelings that these create lead to 
internalized oppression. As Margels and Margels (2010) point out, internalizing discrimination, racism and oppression may lead to patterns of withdrawal, giving up, feeling isolated and feeling not smart/good/capable enough, feeling unwanted and unwelcome.

The above underscores the need for more information gathering by social workers who work with new immigrant population groups. This will help them understand and assess the degree to which immigrants and their children experience the harsh realities of the acculturation process which has been shown, from this study, to negatively affect family relations and limit the immigrant children's ability to overcome obstacles to social mobility. This is a clarion call for cultural competence in social work practice.

\section{CONCLUSION}

For Black African immigrant and refugee youth who were the focus of this study, growing up in Canadian society can be a process fraught with struggles, sometimes traumatic. The conclusion that is drawn from this study is that this one-and-a half generation of Black African immigrant youth face a variety of issues in Canadian society that contradict the values and attitudes promoted in their families and ethnic cultures. For example, in trying to retain one's cultural and ethnic traditions in a new society, the dilemmas and challenges of fitting in constantly arose as a function of negotiating different cultural values. For this generation of Black African immigrant youth, situating themselves within two cultural milieus always involved juggling acts aimed at restructuring and creating a bi-cultural identity.

Coping with these challenges leaves these youth to find a balance within these two social and cultural spheres, thereby demanding a shift in attitudes and behavior to accommodate the differences. This adjustment is usually manifested in the acquisition of a bicultural identity as a means of coping (Hernadez and Charney, 1998). As shown from the study, it is evident that to create a balanced and blended identity, many Black African immigrant youth go through a process of self-questioning, deconstructing and reconstructing of their attitudes, values and beliefs. These difficult processes are all taken in the name of integrating into their new society, Canada. It is a difficult process of navigating two turbulent worlds in the early lives of a vulnerable and fragile population group. The end result, as shown above, for many, has been identity deconstruction which borders on fragmentation and for others an identity reconstruction that creates even more confusion.

\section{REFERENCES}

Appiah, A. and A. Gutmann, 1998. Color conscious: The political morality of race. 1st Edn., Princeton University Press, Princeton, NJ., ISBN: 0691059098, pp: 200.

Barth, F., 1998. Introduction, in Ethnic groups and boundaries the social organization of culture difference. 1st Edn., Waveland Press, Long Grove, ISBN: 0881339792, pp: 153.

Boykin, A.W., 1994. Harvesting culture and talent: African American children and educational reform. In: Schools and students at risk, Rossi, R., (Ed.), Teachers College Press, New York, ISBN: 0807733253, pp: 116-138.

Boykin, A.W., Toms, F.D. 1985. Black Child Socialization: A Conceptual Framework. In: Black Children: Social, Educational and Parental Environments, McAdoo, H.P. and J.L. McAdoo, (Eds.). Sage Publications, Thousand Oaks, Calif, ISBN: 0761920021, pp: 240-240.

Burpee, F.L., 1920. White and black lies. 1st Edn., Christian Workers Union, Framingham, pp: 8.

Carspecken, P. and M. Apple, 1992. Critical qualitative Research. Theory, Methodology and Practice. In: The handbook of qualitative research in education. LeCompte, M.D., W.L. Millroy and J. Preissle (Eds.). Academic Press, San Diego, ISBN: 0124405703 pp: 881-881.

Das G.M. 1998. Gender roles and cultural continuity in the east asian indian immigrant community in the US. Sex. Rol., 38: 953-974. DOI: 10.1023/A:1018822525427

Dei, G. 1998. The politics of Educational Change: Taking Anti-Racism Education Seriously. In: Racism and Social Inequality in Canada. Satzewich, V., (Ed.). Educational Publishing, Inc, TorontoThompson, ISBN: 1550771000, pp: 354-354.

Firmat, P. 1994. Life on the Hyphen: The CubanAmerican Way. 1st Edn., University of Texas Press, United States; United States; pp: 216.

Ghuman, P.A.S. 1991. Best or worst of both worlds? A study of Asian Adolescents. Educ. Res., 33: 121132. DOI: 0.1080/0013188910330205

Hernadez, D.J. and E. Charney, 1998. From generation to generation: The health and well-being of children in immigrant families. 1st Edn., National Academy Press, Washington, DC., pp: 334.

Ladson-Billings, G., 1998. Just what is critical race theory and what's it doing in a nice field like education. Int. J. Qual. Stud. Educ., 11: 7-24. 
Ladson-Billings, G. 2000. Racialized discourses and ethnic epistemologies. In: Handbook of qualitative research. Denzin, N.K. and Y.S. Lincoln (Eds.). Sage Publications, Inc., Thousand Oaks, California, pp: 257-277).

Ladson-Billings, G., 1997: Culturally Relevant Teaching in Action In: Lockwood, A.T. Conversations with Educational Leaders, Contemporary Viewpoints on Education in America, SUNY Press, Albany, ISBN: 0791432882, PP: 254-254.

McDonald, H., 2003. Exploring possibilities through critical race theory: Exemplary pedagogical practices for Indigenous students. James Cook University.

Miller, G. and R. Dingwall, 1997. Context and Method in Qualitative Research. Sage Publications, Thousand Oaks, ISBN: 0803976321, pp: 226.

Moss, A., J. Bucklaschuk and S.R. Anni 2010. Small places, big changes: Temporary migration, immigration and family reunification. Brandon University.

Nagel, J. 1994. Reconstructing ethnicity: Creating and recreating ethnic identity and culture. Soc. Problems, 41: 1-1.

Phinney, J. 1996. When we talk about ethnic groups, what do we mean. Am. Psychol, 51: 918-927.

Portes, A. 1996. The New Second Generation. 1st Edn., Russell Sage Foundation, New York, ISBN: 0871546833, pp: 246.

Portes, A. and R.G. Rumbaut, 1996. Immigrant America: A portrait. University of California Press.

Portes, A. and R.G. Rumbaut, 2001. Legacies: The Story of the Immigrant Second Generation. 1st Edn., University of California Press, Berkeley, Calif, ISBN: 0520228480, pp: 406.
Rumbaut, R.G. 1994. The crucible within: Ethnic identity, self-esteem and segmented assimilation among children of immigrants. Intern. Migr. Revi., 28: 748-794. DOI: 10.2307/2547157

Rumbaut, R.G., 1996. Ties that Bind: Immigration and Immigrant Families in the United States. In: Immigration and Family: Research and policy on US Immigration, Booth, A., A.C. Crouter and N. Landale, (Eds.). Routledge, London, ISBN: 0805821538, pp: 3-45.

Solorzano, D. and T. Yosso, 2002. Critical race methodology: counter-storytelling as an analytical framework. Qualitative Inquiry, 8: 23-44. DOI: 10.1177/107780040200800103

Statistics Canada 2009. Canada at a glance: demography. Statistics and Canada.

Steele, C.M. 2004. Not just a test. Nation New York, 278: 38-40.

Suarez-Orozco, C., M.M. Suarez-Orozco and F. Doucet, 2004. The Academic Engagement and Achievement of Latino Youth. In: Handbook of Research on Multicultural Education. Banks, J.A. and C.A.M. Banks, (Eds.). Jossey-Bass, San Francisco, ISBN: 0787959154, pp: 1089-1089.

Turner, R., 1974. Ethnomethodology. Penguin Books, Harmondsworth, pp: 287.

Van Manen, M. 1990. Researching lived experience: Human Science for an action Sensitive Pedagogy. SUNY Press, Albany, N.Y., ISBN: 0791404269, pp: 202.

Waters, M. 1994. Ethnic and racial identities of second generation Black immigrants in New York City. Int. Migrat. Rev., 28: 795-820.

Zhou, M. 1997. Growing up American: The challenge confronting immigrant children and children of immigrants. Ann. Rev. Soc., 23: 63-95. 